\title{
OS EXEMPLOS DE AUSTIN
}

Jean D. Soares

Doutorando em Filosofia pela PUC-Rio

Resumo: Ocupado com exemplos de nosso dia-a-dia, John L. Austin recolheu casos frequentes de enunciados que inevitavelmente fornecem muita consistência àquilo que descreve como performativos. Porém, ele estranhamente evita tratar de alguns deles, como quando se refere aos performativos da ficção. A partir do estudo de casos, investigaremos os limites de noções centrais de sua obra mais citada, How to do things with words: tais como ato performativo e constatativo, ato locucionário, ilocucionário e perlocucionário. Nosso objetivo é recolher indícios acerca dos limites dos atos de fala para trabalhar exemplos de enunciado desconsiderados ou não tratados pelo autor.

Palavras-Chave: Atos de fala, Exemplos, ficção.

But thoughts are a most interesting, i.e. a confusing case...

Austin, J. L. How to do things with words 
O estardalhaço, ou melhor, a discussão causada pelos trabalhos de John Austin na filosofia do século XX chama a atenção. Não porque se trata de mais um daqueles autores com obras extensas que pensou um novo sistema filosófico, criou um tipo diferente de modelo econômico ou mesmo sugeriu uma revolução social. Longe disso. Austin passou boa parte de sua vida pesquisando um assunto bem específico ao qual se dedicou intensamente. Muito do estardalhaço causado por suas reflexões resulta dos efeitos para o pensamento de uma distinção, que se encontra na primeira conferência de How do to things with words. Este livro tão citado foi obra de editores que tomaram algumas notas de aula proferidas pelo autor na universidade de Harvard em 1955, confrontadas com outras conferências desta mesma época. O que chegou até nós, portanto, é um esboço do que foi dito.

Os editores intitularam a primeira conferência de "Performativos e constatativos". Para nós, que hoje já nos acostumados a ouvir falar de performances, atos performativos, atos de fala, speech acts, não há muito o que estranhar. Os ouvidos filosóficos de 1955, porém, creio eu, se surpreenderam com essa distinção. Por mais óbvio que pareça, o fenômeno a ser discutido pode ter passado despercebido ou mesmo não havia ainda sido formulado de maneira clara. Cito Austin:

Por muito tempo, os filósofos supuseram que o papel de uma declaração [statement] pode ser só o de "descrever" algum estado de coisas, ou "declarar um fato", o que se deve fazer verdadeira ou falsamente. Os gramáticos, de fato, indicaram frequentemente que nem todas as sentenças são declarações: há, tradicionalmente, além das declarações, também questões e exclamações, e sentenças que expressam comandos, desejos, ou concessões. E sem dúvida, os filósofos não pretenderam negar isso, apesar de seu uso um tanto vago de "frase" como "declaração". Sem dúvida também, ambos, gramáticos e filósofos sempre perceberam que não há meios fáceis de distinguir até questões, comandos, entre outras coisas, de declarações através de poucos e incipientes recursos gramaticais disponíveis, tais como a ordem das palavras, o modo verbal, etc; porém, talvez não seja comum dar atenção às dificuldades que este fato obviamente apresenta. De que modo decidimos o que é o quê? Quais são os limites e definições de cada uma? 1

1 AUSTIN, How to do things with words, pp.1-2. [Tradução nossa, cotejada com a tradução para o português de Danilo Marcondes]. 
De saída, o autor distingue seus interlocutores, gramáticos e filósofos que, com cautela, evitam esbarrar no limite dos campos que tocam. Mas John Austin esbarra. Ao se perguntar sobre os limites de cada um, ele percebe o campo de possibilidades sobre o qual acaba por trabalhar. Aí se encontram os exemplos que até então eram olhados com uma severa desconfiança por parte de muitos filósofos (que os excluíam), e com uma intensa curiosidade pelos gramáticos.2

Ao longo do livro, notamos curiosamente que os exemplos são de pelo menos dois tipos. Alguns, mais "caricatos", servem às definições que são pretendidas pelo autor. Nesses casos, a ligação entre o que ele pretende definir e o que está sendo definido parece não deixar margem. São os casos dos exemplos de performativos dados no início do livro: "Aceito esta mulher como minha legítima esposa" no decurso de uma cerimônia de casamento, por um dos nubentes diante do juiz; "Batizo este navio com o nome de Rainha Elizabeth", quando, com uma garrafa, batiza-se um navio; "Lego a meu irmão este relógio", como ocorre em um testamento; e "Aposto cem cruzados como vai chover amanhã". Em todos esses casos, o que está em jogo é o que este ato faz quando é dito, ou seja, o que acontece quando e porque o enunciado foi dito. Nessas circunstâncias, quando alguém diz "Aceito", "Batizo", "Lego" ou "Aposto" não relata ou descreve, como um narrador de sua própria vida, as circunstâncias em questão - esse alguém as realiza. São enunciados que, a despeito de sabermos se podemos avaliar o seu valor de verdade, se fazem valer quando ditos nas circunstâncias adequadas, por isso podem ser felizes ou infelizes, bem sucedidos ou não em sua enunciação/declaração (uso declaração e enunciado, neste artigo como sinônimos). Se alguém pede desculpas, esse enunciado pode ser bem ou mal sucedido, dependendo do interlocutor; e se alguém aposta que vai chover amanhã, o enunciado em questão pode ser feliz ou infeliz. Esses exemplos facilitam a percepção disso a que Austin chama de enunciado performativo. Por sua simplicidade e eficácia, podemos chamá-los de

2 Sobre abordagens anteriores próximas à elaborada por Austin, ver CASSIN et al., "Speech Acts" In: Dictionary of Untranslatables, pp. 1037-46. 
exemplos de definição, pois surgem em todas as etapas do livro em que Austin procura tornar evidente para nós o que pensa.

O autor, porém, não procede sempre dessa maneira. Há ao longo de todo livro um conjunto de exemplos que, por uma questão de praticidade, chamei de complicadores. Através deles, o autor insinua algumas dificuldades que ele mesmo encontra com suas definições. Antes de colhermos alguns desses casos, gostaria de salientar que lidar com os exemplos complicadores me parece ser uma das grandes dificuldades da leitura do livro de Austin. Nunca se percebe bem, graças a eles, aonde o autor quer chegar, até que ponto defende o que está apresentando. Um leitor atento pode, mais de uma vez, se perguntar: será mesmo que ele está à procura de performativos puros? Será que o fato de se tratarem de notas compiladas e coligidas por alunos não exigiria supor outras questões? Por uma demanda de honestidade intelectual, ele parece se ver obrigado a explorar toda a riqueza possível da constatação que the fascina, qual seja, de que as palavras, pelo menos em alguns casos, parecem fazer. Vamos a eles.

Após distinguir diversos tipos de infelicidades, ou seja, de atos performativos que por alguma razão não fazem o que desejavam fazer,3 Austin põe questões sobre as infelicidades. Uma delas sobre a completude da classificação, de sua capacidade de abarcar a maior diversidade de exemplos possíveis, acaba por derivar para uma questão importante: como lidar com os enunciados da ficção, ditos em um palco, em um poema, ou mesmo em um monólogo? A posição de Austin:

Um proferimento performativo, por exemplo, será, de uma maneira peculiar, nulo ou vazio se dito por um ator em um palco, ou introduzido em um poema, ou falado em um solilóquio. (...) A linguagem nessas circunstâncias não é inteligivelmente - usada a sério, mas de modo parasitário em relação ao seu uso normal - maneiras pelas quais cai sobre a doutrina dos estiolamentos da linguagem. Tudo isso excluímos

3 No esquema, Austin distingue: A.B - Desacertos; a) más aplicações (que levam a um ato rejeitado), ou seja, não está bem usado para tal situação; b) más execuções (que levam a um ato prejudicado, do tipo falha ou tropeço), como no caso do ato falho, em que se quer dizer uma coisa e se diz o contrário; $\Gamma$ - abusos (atos professados mas vazios, como as insinceridades). (AUSTIN, How to do things with words, p. 19) 
de nossa consideração. Nossos proferimentos performativos, felizes ou não, são para ser compreendidos como emitidos em circunstâncias ordinárias. 4

Alguns podem argumentar dizendo que se trata de um não-exemplo, já que o autor, ao contrário do que usualmente faz, não ilustra com um enunciado - que está sendo excluído. Podemos deduzi-lo da estrutura de sua argumentação. Se, em um casamento de festa junina, alguém diz que aceita a noiva; se, em uma peça sobre o Titanic, alguém diz que o batiza; se alguém, em um monólogo de stand-up comedy, aposta consigo mesmo; ou se alguém brinca de ler o testamento alheio; em nenhuma dessas circunstâncias poderíamos considerar esses enunciados como performativos, eles seriam nulos ou vazios, não fariam nada efetivamente, porque se o fizessem incorreríamos no risco de estiolar a linguagem. Austin alerta, mas não nos diz o que é esse estiolamento. Botanicamente, trata-se do esticar do caule a partir da semente quando há falta de luz - um crescimento com pouca vitalidade e cor. Em geral, o campo semântico refere-se a um enfraquecimento ligado, portanto, à demasiada ampliação de alguma coisa.

Já que ele exclui este caso, por que considerá-lo como um exemplo complicador? Exatamente porque ele nota o risco e o evita. Austin percebe que poderia haver algo de performativo nesses casos, mas isso ampliaria demasiado o escopo dos performativos, levando-o a ter que postular que cada frase dita nestas circunstâncias faz alguma coisa. Ao dizer que aceita na festa junina, a personagem se faz noiva, bem como em todos os outros casos, o sujeito falante fabrica aquilo que enuncia. Ainda assim poderíamos responder dizendo que estes usos não são usos sérios, ordinários da linguagem. E aí ainda encontramos complicações. Como não dizer que os enunciados de um ator nunca são tomados a sério em uma peça, se por muitas vezes saímos a refletir bastante após presenciar sua interpretação? Como não dizer que uma aposta consigo mesmo em um monólogo de stand-up comedy por mais risível que pareça não possa estar sendo feita com um comprometimento profundo daquele que a realiza? Como considerar vazio, por exemplo, o uso da situação 
teatralizada para a enunciação em uma circunstância irônica, talvez mais ordinária do que imaginemos? Austin parecia antever tudo isso e por isso exclui os enunciados não sérios.

Outro caso de exemplo complicador, desta vez sobre as relações entre enunciado performativo e verdade: na quinta conferência, quando trata dos "Critérios possíveis de performativos", Austin discute o enunciado "Desculpe-me". Não parece haver questões sobre sua "performatividade", ele pode ser feliz (ou infeliz), quando dito nas circunstâncias certas.5 Suas questões se dirigem à possibilidade de ser também verdadeiro. Se "Desculpe-me" é feliz, então 1) a declaração de que estou pedindo desculpas é verdadeira; 2) a declaração de que se dão certas condições de enunciação (pessoa, procedimentos e circunstância adequados) tem que ser verdadeira. Há o perigo, portanto, de anular a distinção. Apesar de afirmar a sua convicção aqui e ali, a dada altura nesta conferência ele diz:

Contraste-se o fato de que ao me desculpar, o que depende do performativo "Desculpe-me" ser feliz, com o caso da declaração "João está correndo", cuja verdade depende de ser fato ou o caso de João estar correndo. Mas talvez este contraste não seja tão sólido: porque, para tomar essas declarações de antemão, conectado com o proferimento "João está correndo" está a declaração "Estou afirmando que João está correndo" - e cuja verdade pode depender da felicidade de "João está correndo", bem como a verdade de "Estou me desculpando" depende da felicidade de "Desculpe-me". E para tomar os performativos em segundo lugar: conectado com o performativo (suponho que o seja) "Alerto-te que o touro está prestes a te pegar" está o fato, se é este o caso, de que o touro está prestes a te pegar - se o touro não está, logo de fato a afirmação "Alerto-te que o touro está prestes a te pegar" está aberta a críticas, mas de nenhum dos modos pelos quais até agora caracterizamos como variedades de infelicidade. Não deveríamos neste caso dizer que o alerta é vão - ou seja, que ele não alerta, mas apenas ganhou forma de advertência; tampouco que ele é insincero -

5 Talvez eu esteja a abrir um parêntesis para uma objeção infundada, mas não há outro motivo de saber se serei feliz neste caso a não ser abrindo-o. Ao ler este caso, sempre me pergunto: esse enunciado alguma vez pode ter sido feliz, se dizê-lo resulta sempre de uma circunstância desagradável? Com isso, Austin só quer dizer que ele se efetiva, isso é certo, mas não estaria ele, sem querer, levandonos a postular uma espécie de ética utilitária da linguagem subjacente a essa distinção? Explico: não será feliz, bem utilizado só porque realiza algo efetivamente para um fim? Ele não estará excluindo aí, uma vez ainda, enunciados que não têm finalidade pré-definida, mas talvez realizem alguma coisa, como é o caso dos enunciados da ficção? Sobre a relação entre negação e os atos de fala, ver MARCONDES, "Aspectos pragmáticos da negação”, pp.17-29. 
sentir-nos-íamos muito inclinados a dizer que o alerta é falso, ou melhor, enganoso/equivocado [mistaken], enquanto declaração. Então, essas considerações de felicidade e infelicidade podem infectar as declarações (ou algumas declarações) [no primeiro caso] e [no segundo caso] as considerações de verdade ou falsidade podem infectar os performativos (ou alguns performativos). 6

O passo que Austin dará em seguida é buscar um critério que evite a "infecção" dos performativos pelos constatativos, dado que só os últimos poderiam ter valor de verdade. As conferências então perseguem esse critério que permitiria estabelecer qual é o performativo puro. Explicando sumariamente: se não tivermos um critério gramatical sólido - o que Austin acaba por defender na quinta conferência - temos de perceber as circunstâncias do ato e como alguns desses elementos gramaticais surgem. Ele parece dar ênfase aos verbos (ver XII Conferência - Classes de Força ilocucionária) e às preposições (VIII Conferência - Atos Locucionários, llocucionários e Perlocucionários) que permitiriam circunscrever o ato de fala.

À parte da busca por critério, um dos esforços constantes das conferências, os exemplos desse trecho supracitado mostram a consciência que tinha o autor da relação entre a feliz execução de um performativo e a possível verdade que esse contenha. Por mais que se tente separar ambos os domínios, o autor acaba por se deparar em seus exemplos com a ambiguidade do que está dito em um alerta, que pode tanto estar fazendo algo quanto constatandoo verdadeiramente. $O$ mesmo enunciado pode estar muitas vezes declarando e fazendo algo como o exemplo complicador, "Desculpe-me" acabou sugerindo.

Uma de suas tentativas de conter essa ambiguidade é separar aspectos do performativo com a distinção entre ato locucionário, ilocucionário e perlocucionário, e as forças que cada um dispõe quando alguém fala (ver VIII e IX conferências). Em busca de um performativo, é preciso distinguir-lhe os atos que estão envolvidos na sua produção. Segundo Austin, para que haja um performativo, é preciso: 
- um ato locucionário - alguém que simplesmente diz algo, do tipo, "Volto já";

- o que já no ato de locução da frase pode implicar em algo que não está dito, proporcionando assim um ato ilocucionário, algo que se faz através disso que se diz, que é gerado pelo ato de dizê-lo: quando alguém diz "Volto já", faz uma promessa de retorno imediato. Essa promessa surge graças a costumes e convenções compartilhados, ou seja, pelas forças ilocucionárias envolvidas nesse enunciado;

- por fim, as ações dos interlocutores que recebem essa mensagem permitem perceber quais os efeitos e consequências de tal declaração - se ficam à espera da pessoa querida, se fogem daquela pessoa inoportuna ou se trocam de canal quando o âncora do programa diz que o seu programa "volta já" esses são exemplos de atos perlocucionários, que estão ligados ao que foi dito, ao seu redor, vinculados a ele enquanto efeitos derivados do performativo em questão.

Vale lembrar que o autor, no final da XI conferência, acaba admitindo que em um constatativo abstraímo-nos de seus aspectos ilocucionários (ou seja, que o tornam capaz de fazer algo enquanto fala) utilizando uma noção "supersimplificada" de correspondência com os fatos que absorve o aspecto ilocucionário; bem como no caso de um performativo, em que damos o máximo de atenção à força ilocucionária (que permite fazer ao dizer) e nos abstraímos da dimensão da correspondência com os fatos.

Gostaria de partilhar algumas impressões que ficaram após me debruçar sobre esses e exemplos que não tive tempo de expor. A primeira é a de que Austin apesar de parecer lutar pela distinção entre constatativos e performativos, nos indica diversos exemplos capazes de dissolver a distinção, como no caso do alerta do touro citado, o que poderia nos levar a pensar que qualquer enunciado pode ser performativo. A segunda é a de que Austin evita escolher complicadores políticos e jurídicos. Pergunto-me, por exemplo, a que ponto ele chegaria se considerasse as declarações de um réu de guerra como Eischmann ou mesmo dos juízes deste. Enquanto ativermo-nos a casos como "A sessão está aberta" talvez não percebamos a radicalidade de outros enunciados políticos. 
Uma última impressão é de que Austin talvez fosse capaz de repensar algumas de suas hipóteses sobre o estiolamento da linguagem, considerando enunciados da ficção. Até que ponto, me pergunto, dizer que

O poeta é um fingidor.

Finge tão completamente que chega a fingir que é dor a dor que deveras sente.

(Trecho de "Autopsicografia", Fernando Pessoa)

pode ser lido como um constatativo sem ser um performativo? Ou mesmo não ser um performativo? Esses enunciados não estariam a fazer efetivamente algo a dizer, mesmo estando em um regime que estiola a linguagem? Impressões ditas (e quem sabe feitas) enfim, por um falante de português.

\section{REFERÊNCIAS BIBLIOGRÁFICAS}

AUSTIN, J. L. How to do things with words. Harvard: Harvard Univ. Press, 1975.

AUSTIN, J. L. Quando dizer é fazer. Trad. Danilo Marcondes Filho. Porto Alegre: Artes Médicas, 1990.

CASSIN, B; APTER ; E. LEZRA, J; WOOD, M. et al. Dictionary of untranslatables. New Jersey: Princeton University Press, 2014.

MARCONDES FILHO, D. "Austin". In: Textos básicos de linguagem. Rio de Janeiro: Jorge Zahar, 2010.

. "Aspectos pragmáticos da negação". In: O que nos faz pensar, no 23. Rio de Janeiro: PUC - Rio, 2008.

PESSOA, F. O Eu profundo e os outros eus. Seleção de Afrânio Coutinho. Rio de Janeiro: Nova Fronteira, 2006. 